\title{
Democracy belief systems in Europe: cognitive availability and attitudinal constraint
}

\author{
Enrique Hernández (i) \\ Department of Political Science, Universitat Autònoma de Barcelona, Bellaterra, Spain \\ E-mail: enrique.hernandez@uab.cat
}

(Received 15 February 2019; revised 29 October 2019; accepted 30 October 2019; first published online 04 December 2019)

\begin{abstract}
There is a growing interest in analyzing what citizens think about democracy. However, gauging citizens' opinions about a complex concept such as democracy might be hindered by the apparent low levels of political sophistication of mass publics. This paper contributes to the emerging literature on citizens' views and evaluations of democracy by analyzing to what extent ordinary citizens are capable of developing structured opinions about democracy and its constitutive principles. For this purpose, the paper adapts Converse's notion of political belief systems to analyze the articulation of individuals' democracy belief systems (DBS). The first goal of this paper is to conceptualize and operationalize the main components of individuals' DBS: cognitive availability, horizontal constraint, and vertical constraint. Drawing on data from the sixth round of the European Social Survey, the second goal is to describe the articulation of DBS in Europe. The third and final aim of this paper is to trace the most relevant individual- and country-level correlates of the articulation of the three components of DBS. In line with recent findings about political belief systems in other policy domains, the results indicate that most Europeans have coherently structured attitudes about democracy. However, even if the results imply that Europeans have a relatively articulated DBS, the empirical analysis also reveals some individual- and country-level variation in the articulation of specific components of DBS.
\end{abstract}

Keywords: political attitudes; democracy; survey; attitudinal constraint; political support

\section{Introduction}

There is a growing interest in identifying citizens' democratic aspirations or the way in which they conceive democracy (Dalton et al., 2008). This interest has been motivated by the possibility that individuals may not share a common idea of democracy and by the implications this may carry for the study of political support. Recent studies have expanded this inquiry and, besides democratic aspirations, they also analyze whether citizens evaluate that these aspirations are fulfilled (Ferrín and Kriesi, 2016; Quaranta, 2018). Moreover, analyses of these attitudes indicate that the specific ways in which citizens think about democracy are consequential for their political engagement and their likelihood of supporting populist and challenger parties (Hernández, 2018; Oser and Hooghe, 2018).

These studies represent a significant contribution for the literature on attitudes toward democracy. However, before settling on the relevant question of how individuals understand and evaluate democracy, and the implications this may carry for political behavior, we should ask ourselves to what extent ordinary citizens are capable of elaborating opinions about complex concepts such as democracy and democratic principles in the first place. Democracies and their constitutive 
principles are abstract and multidimensional entities frequently discussed by political scientists. However, average citizens might have little insight about these concepts.

Traditionally, it has been argued that the political belief systems (PBSs) of mass publics lack structure and coherence and that ordinary citizens lack knowledge about simple political facts (Converse, 1964; Delli Carpini and Keeter, 1996). If this were actually the case, it would be pointless to measure and analyze the democratic aspirations and evaluations of ordinary citizens. However, recent evidence indicates that the PBSs of citizens are much more articulated and structured than it was previously assumed (Goren, 2013; van Elsas, 2015; Freeze and Montgomery, 2016). According to this perspective, it should be possible to analyze in detail what individuals think about democracy and its constitutive principles. However, the extent to which citizens have an articulated and coherently structured belief system about democracy is still an open question.

This paper contributes to the literature on citizens' understanding and evaluations of democracy through an analysis of the articulation of individuals' belief systems about democracy. For this purpose, the paper adapts Converse's notion of PBSs to analyze the articulation of individuals' democracy belief systems (DBS) through data from the sixth round of the European Social Survey (ESS). The first goal of this paper is, therefore, to conceptualize and operationalize the main components of individuals' DBS. The second goal is to describe the articulation of DBS in Europe. The third and final goal is to trace the most relevant individual- and country-level correlates of the articulation of DBS.

In line with recent findings about domain-specific PBS, the empirical results support the idea that most Europeans have coherently structured attitudes about democracy. However, even if the results indicate that most Europeans have a relatively articulated DBS, the empirical analysis also suggests that there are some relevant individual- and country-level differences in the articulation of specific components of DBS.

These findings have relevant implications for future and existing studies on political support. Knowing that one can reliably analyze what citizens think about democracy is of the utmost relevance to study phenomena such as democratic backsliding, decreasing support for democracy among the youth, increasing democratic discontent, or the populist upsurge (see Foa and Mounk, 2017).

\section{Theory}

Converse's (1964) notion of PBS provides the analytical framework to study the articulation of individuals' beliefs about democracy. A PBS can be conceptualized as 'a configuration of ideas and attitudes in which the elements are bound together by some form of constraint or functional interdependence' (Converse, 1964: 207). A person's political cognitions together with those with which they are constrained or interrelated form her PBS (Luskin, 1987). From this definition, we identify two central components of PBS: the number of cognitions or attitudes available in an individual's belief system and the coherent structuration of these cognitions or attitudes. Therefore, an articulated DBS will be one in which, first, a broad number of cognitions about how democracy ought to be (democratic aspirations) and how it works in reality (democratic evaluations) are available, and, second, in which these cognitions or attitudes are coherently organized or constrained. Following Goren (2013), I refer to the first element as cognitive availability and to the second as attitudinal constraint.

Studies analyzing PBS focus, predominantly, on attitudinal constraint and disregard cognitive availability. However, the fact that a set of cognitions or attitudes about a political issue are available in one's mind is a precondition for the existence of attitudinal constraint. The latter cannot exist without the former. For a set of attitudes to be coherently structured, these attitudes need first to be available in a belief system. As a consequence, by exclusively focusing on attitudinal 
constraint, most previous studies exclude those citizens with low levels of cognitive availability altogether. ${ }^{1}$ Hence, an analysis of cognitive availability should be the first step when studying the articulation of belief systems in any domain.

Cognitive availability is, therefore, the fundamental component of DBS, and it refers to the number of cognitions about democracy that are accessible in a belief system. In order to express their democratic aspirations, and to evaluate the extent to which these aspirations are fulfilled in the countries where they live, cognitions about democracy and its constitutive principles must be available in citizens' belief systems. In the absence of cognitive availability, attitudes toward democracy cannot be constrained.

Political cognitions are not directly apprehensible, though. They must be deduced from what a person says or does (Luskin, 1987). Therefore, cognitive availability must be inferred from external manifestations. One approach to gauge availability is to rely on opinion-holding measures (Berinsky, 2005; Dalton and Shin, 2014). Accordingly, when a survey respondent admits ignorance (i.e., that she 'doesn't know'), the presumption is that no attitude or cognition resides in memory. That is, the cognition or attitude is unavailable.

In this paper, I implement this approach by relying on questions that ask citizens how important they think certain democratic principles (e.g., the rule of law) are for democracy in general (democratic aspirations), and the extent to which they evaluate that these same principles are applied in their countries (democratic evaluations). Hence, cognitive availability captures, first, whether or not a cognition about a certain democratic principle itself (e.g., the rule of law) is available in the respondent's belief system, and, second, if that cognition can be related to democracy. To relate a democratic principle to democracy, one must see the logical connection between that principle and democracy. Take the principle of the rule of law as an example. To link that concept to an ideal notion of democracy, citizens first need to understand what the concept of the rule of law means, and, second, they need to consider whether and to what extent the rule of law is related to democracy (Ferrín, 2012).

In contrast to the PBS literature, studies of individuals' conceptions of democracy have paid some attention to what I here define as cognitive availability. These studies describe individuals' capacity to articulate a conception of democracy or their democratic aspirations (Bratton et al., 2005; Dalton et al., 2008; Hernández, 2016), as well as their capacity to evaluate the performance of different dimensions of their democracies (Dalton and Shin, 2014; Gómez and Palacios, 2016). Their conclusion is that a majority of the population is capable of articulating a fully fledged conception or evaluation of democracy.

Cognitive availability is a necessary but not sufficient condition for an articulated DBS, though. Individuals' attitudes might not be coherently structured, since their declared attitudes might just be a reflection of 'non-attitudes' produced at random (Converse, 1970). For this reason, an articulated belief system also requires attitudes to be bound together by some form of constraint or functional interdependence. Attitudinal constraint is defined as the success we would have in predicting, given initial knowledge that an individual holds a specified attitude, that he holds certain further ideas and attitudes' (Converse, 1964: 207). Constraint is, therefore, a relational property of attitudes, which implies that the different attitudes an individual holds in a given political domain are structured forming a coherent whole. In fact, attitudinal constraint has been considered a manifestation of coherence, sophistication, and consistency (Rohrschneider, 1993; van Elsas, 2015; Freeze and Montgomery, 2016).

Attitudinal constraint can take two forms: horizontal and vertical (Hurwitz and Peffley, 1987). Horizontal constraint implies that two or more attitudes at the same level of abstraction are related in a predictable way. For example, knowing that someone favors increasing government spending in

\footnotetext{
${ }^{1}$ Most previous studies exclude those respondents who fail to provide a valid answer to any of the attitudinal items considered. This is for good reason since those who fail to provide a valid answer cannot be included in the analysis of attitudinal constraint, because when an attitude is not available it cannot be, by definition, constrained or unconstrained.
} 
social housing, we would predict that this person would also favor greater government spending in healthcare. Vertical constraint implies that some superordinate value, priority, or attitude at a higher level of abstraction structures attitudes on more specific issues at a lower level of abstraction. The most common instance of a superordinate or general value that shapes attitudes on more specific and less abstract issues is ideology. Continuing with the previous example, issue-specific attitudes toward government spending on social housing and healthcare should derive from a broader stance toward the involvement of the government in the economy that is reflected in one's ideology.

It is important to note that assessing the presence of horizontal constraint and vertical constraint by analyzing the interrelationship between attitudes requires a theoretical framework that specifies a priori 'what goes with what'. It is possible to specify such a theoretical model for how democratic aspirations about specific principles of democracy should relate among themselves (horizontal constraint) and for how these aspirations should relate to superordinate attitudes (vertical constraint). However, this is not the case for the evaluations about how these same democratic principles are applied in a country, since their interrelationship and their relationship with attitudes at higher levels of abstraction will be dependent on the specific democratic performance of each country. Therefore, the analysis of the constraint of DBS is limited to democratic aspirations.

Most studies of PBS argue that in the presence of horizontal constraint, attitudes tapping a common domain and located at the same level of abstraction should be strongly correlated. However, in the case of DBS, I draw on the logic of a hierarchical structuration of the model of liberal democracy proposed by Kriesi et al. (2016) to argue that correlation should not be the determinant of horizontal constraint. Constraint will be determined by the fact that democratic aspirations for principles of democracy pertaining to the liberal model of democracy are hierarchically structured in a coherent way. ${ }^{2}$ Hence, the fact that democratic aspirations that tap a common domain and are located at the same level of abstraction are related in a predictable (hierarchical) way will denote horizontal constraint.

The idea that the importance individuals attribute to different principles of the liberal model of democracy (e.g., free elections, press freedom) should be hierarchically structured derives from the fact that some of these principles, such as free elections, are considered indispensable in most normative theories of democracy (Fuchs, 1999). More demanding theoretical models of liberal democracy always include these basic principles, which are complemented with additional principles (e.g., press freedom or an ideologically differentiated partisan offer). One would expect individuals to follow a similar logic when determining the importance of different principles of democracy for an ideal democratic system. Individuals who attribute a high importance to nonessential principles of the liberal model should also attribute an equal or higher importance to its basic principles. Hence, in the presence of Horizontal constraint, individuals' democratic aspirations should be hierarchically structured in a predictable way.

Take as an example, the principles of the freedom of elections and the need for a differentiated partisan offer. Table 1 presents an example of the democratic aspirations of four individuals $i$ for these two principles of democracy. For simplicity, the democratic aspirations for these two principles can only take two values: high and low. Individuals $i_{1}, i_{2}$, and $i_{3}$ differ in the importance they attribute to these two principles in their ideal conceptualization of democracy. However, they all have a logical hierarchical structuration of their beliefs: $i_{1}$ thinks that both principles are equally important; $i_{2}$ thinks that none is important (this might indicate that she is not a democrat, but her DBS is still coherently structured); $i_{3}$ thinks that the essential element is important while the nonessential one is not. In the case of $i_{4}$, though, her beliefs about these two principles of democracy are not coherently structured. It is illogical that someone attributes a high importance to political parties being ideologically distinct but, at the same time, attributes a low importance to the fact that elections are conducted freely. This should be taken as an indication of an incoherently structured DBS.

\footnotetext{
${ }^{2}$ See 'Data and methods' section for a justification of the restriction of the analysis of constraint to the liberal model of democracy.
} 
Table 1. Importance attributed to two principles of democracy among four individuals $i$

\begin{tabular}{lcccc}
\hline Principle of democracy & $i_{1}$ & $i_{2}$ & $i_{3}$ & $i_{4}$ \\
\hline Free elections & High & Low & High & Low \\
Differentiated partisan offer & High & Low & Low & High \\
\hline
\end{tabular}

In the case of vertical constraint, a DBS will be constrained if a general value located at the center of an individual belief system structures these specific democratic aspirations in a predictable way. The importance attributed to being able to live in a democracy (i.e., preference to live in a democratic country without reference to any specific democratic principle) can be considered a general belief located at the center of individuals' belief systems. In the presence of vertical constraint, specific democratic aspirations - which are located at a lower level of abstraction or a more peripheral position in belief systems - should be structured by this generic preference to live in a democratic regime. A stronger desire to live in a democracy (generic democratic preference) should be positively correlated with higher democratic aspirations. If, for a given citizen, there is a strong correspondence between this more abstract belief and her specific democratic aspirations, her DBS will be vertically constrained.

\section{The articulation of DBS}

Given recent findings about the articulation of PBS (see e.g., Rohrschneider, 1993; van Elsas, 2015), one would expect Europeans to have an articulated DBS. That is, a DBS in which, first, a broad number of cognitions about democracy are available and, second, in which these cognitions or attitudes are horizontally and vertically constrained. However, at the same time, we might still find some individual- and country-level variation in the degree of articulation of DBS.

The literature on how people learn and develop attitudes about politics provides us with some clues about the factors that might be related to the articulation of DBS. The main means to learn and develop structured attitudes about political objects are direct experience with that object and exposure and comprehension of information about the object (Bizer et al., 2004; Goren, 2013). Hence, one's ability, motivation, and opportunities to learn about politics are crucial for the development of structured political cognitions (Delli Carpini and Keeter, 1996).

Education should be an important factor for the development of DBS not only because it is related to an enhanced capacity to process, coherently store, and express opinions about democracy, but also because it is positively related to direct and indirect exposure to information about democracy (Nie et al., 1996). Hence, there are two potential mechanisms linking higher education to broader and more coherently organized attitudes: enhanced cognitive abilities and a greater likelihood of being exposed to information about democracy.

The importance one attributes to an object should also be linked to the development of structured attitudes. Object importance means that a person cares and is concerned about a given issue, and as a consequence, she is more motivated to monitor information and learn about that issue (Bizer et al., 2004). Political interest - a proxy for the general importance that politics has in someone's life - reflects one's motivation to learn and be informed about politics. As a consequence, those who are more interested in politics should have a more articulated DBS.

Direct experience with an attitude object should also contribute to the development of broader and more structured attitudes (Eagly and Chaiken, 1993). In line with this argument, institutional learning theories acknowledge the importance of a nation's institutional framework for the formation of attitudes (Rohrschneider, 1999). Interacting with a given political system increases the opportunities and motivation to learn and internalize the prevailing norms of that institutional framework. In democratic contexts, citizens will be incorporated to the democratic game, and they will have greater chances of directly interacting with democratic institutions. In contrast, in young democracies, individuals lack this prolonged experience with democratic institutions, and as a 
result, they have greater difficulties with evaluating the performance of democratic institutions (Torcal, 2006). Therefore, in countries with a prolonged experience of democracy, we should find more articulated DBS. In addition, in these contexts, there should also be lower inequalities in the articulation of DBS. Information rich contexts reduce inequalities in political knowledge (Fraile, 2013). By increasing the opportunities of learning about democracy, democratic regimes are expected to lead to a reduction of the impact of factors that might generate inequalities in the articulation of DBS, such as, for example, education.

Finally, previous studies of PBS indicate that there should be a significant linkage between the constraint elements of belief systems (Rohrschneider, 1993). In the particular case of DBS, horizontal constraint and vertical constraint should be positively related. That is, those citizens who have a more coherent structuration of their specific democratic aspirations (horizontal constraint) should also have a greater correspondence between these specific aspirations and their general preference to live in a democratic country (vertical constraint). This is because a noncoherent horizontal structuration of democratic aspirations should prevent a strong correspondence with any other attitude. Here, it is important to reiterate that, at the individual level, the remaining element of DBS (cognitive availability) cannot be related to horizontal constraint or vertical constraint in any way, since cognitive availability is a precondition for the existence of any form of constraint.

\section{Data and methods}

The analyses draw on data from the 2012 round of the ESS, fielded in 29 European countries. This survey includes a battery of questions that ask respondents their opinion about the importance they attribute to 19 different principles for an ideal democratic system (democratic aspirations), followed by questions about their evaluation about the extent to which 17 of these principles are applied in their countries (democratic evaluations). These questions refer to different principles of democracy: rule of law, freedom of elections, government justification of decisions, media reliability, press freedom, the protection of minorities' rights, political parties' freedom, political deliberation, direct democracy, vertical accountability, differentiated partisan offer, freedom of expression, government responsiveness, horizontal accountability, migrants' voting rights, power sharing, government responsibility toward other European governments, the government's role in protecting citizens against poverty, and the government's role in reducing income inequalities. ${ }^{3}$

\section{Cognitive availability}

I operationalize cognitive availability through opinion-holding measures. When a respondent admits that she does not know the answer when asked to state her opinion about the importance of a given principle for an ideal democratic system or for how it is applied in her country the presumption is that a cognition about that principle is not available in her belief system. Cognitive availability is operationalized by relying on the 19 principles respondents who were enquired about with respect to their democratic aspirations, and the 17 principles capturing their democratic evaluations. Each of the principles takes the value 1 if the respondent gave a don't know answer and the value 0 otherwise.

I assess if don't know answers to these questions capture a latent dimension and can be aggregated into an overall measure of cognitive availability through Mokken scaling. This method tests if responses to different questions are governed by a latent trait (e.g., one's ability). The logic underlying Mokken scaling is that each of the items can be hierarchically ordered according to some characteristic, for example, their difficulty. In the case under consideration, this is indicated by the number of don't know answers to each of the items. Items with a larger share of don't know answers are more difficult. If responses to each of these items are governed by a latent trait (i.e., cognitive availability), those who have higher availability should only fail to respond to those more difficult items, while those who have lower availability should fail to respond to easier items

${ }^{3}$ Details about the question wording of all the survey items used in this paper can be found in Appendix A. 
as well. If this is the case, the items form a Mokken scale and they can be used to measure the latent trait by adding each of the items.

The results show that all items have good scalability properties (Loevinger-H higher than 0.3 for all items) and that the resulting scale satisfies a Mokken scale (Loevinger-H of scalability equals 0.47). ${ }^{4,5}$ These results indicate that these items can be used to compute an additive cognitive availability scale, and they also support the idea that don't know answers are governed by a latent trait and are, therefore, not likely to be generated at random. The cognitive availability variable is computed by adding up all the cognitive availability items; it is rescaled to range between 0 and 100; and it is reversed so that higher values indicate higher levels of cognitive availability (i.e., a lower number of don't know answers).

\section{Horizontal constraint}

Following Converse (1964), most studies rely on correlations between issues located at the same level of abstraction to measure horizontal constraint. However, as Luskin (1987) pointed out, the problem of the most commonly used techniques to assess attitudinal constraint is that they only produce group-level measures of constraint. Even if they are estimated using data at the individual level, individual-level estimates of horizontal constraint cannot be obtained.

Without directly relating to the literature on attitudinal constraint, but focusing on a closely related topic, van Elsas (2015) argues that assessing the internal consistency of political attitudes requires a method that considers structured differentiation in answering patterns as a measure of consistency. For this reason, she relies on Mokken scaling to assess the internal consistency of individuals' political trust. In this paper, I adopt the same approach and I exploit the potential of Mokken scaling to estimate a measure of horizontal constraint for each respondent.

Like any other approach to measure horizontal constraint, this method requires me to select a set of theoretically related items. To measure constraint, I draw on the logic of a hierarchical structuration of the liberal model of democracy. This model comprises the following principles of democracy: rule of law, freedom of elections, horizontal accountability, media reliability, vertical accountability, government justification, minorities' rights, parties' freedom, press freedom, differentiated partisan offer, and political deliberation.

To generate an individual-level measure of horizontal constraint, I first estimate a Mokken scale model that includes all the items measuring liberal democratic aspirations. Democratic aspirations are measured through a $0-10$ scale in order to capture the importance of respondents' attribute to each principle of democracy in an ideal democratic system. Therefore, I estimate a polytomous Mokken scale (Hardouin et al., 2011). Table 2 shows that all the item-specific and scale Loevinger parameters have an acceptable fit. This could be taken as a first indication that, on average, Europeans' liberal democratic aspirations are coherently structured or horizontally constrained. ${ }^{6}$

To compute an individual-level measure of horizontal constraint, I estimate the Guttman errors induced by each individual. For each pair of items, these errors capture whether an individual attributes a higher importance to a lower ranked principle (e.g., deliberation) than to a higher ranked principle (e.g., free and fair elections). From the Mokken scale model, the total number of errors of each individual $\left(e_{\mathrm{n}}\right)$ can be computed. The greater $e_{\mathrm{n}}$ the more times each individual has violated the hierarchy of the items, as defined by the response pattern of all respondents included in the sample. Hence, to compute the measure of horizontal constraint, $e_{\mathrm{n}}$ is simply reversed and rescaled to range between 0 and 100, with higher values indicating a higher level of horizontal constraint. This operationalization has two clear advantages. First, it allows us to analyze individual-level variation in horizontal constraint. Second, it provides a threshold to determine whether or not an individual has a horizontally constrained DBS (see below).

\footnotetext{
${ }^{4}$ Mokken (1971) indicates that scales and items with a scalability coefficient higher than 0.3 satisfy a Mokken scale.

${ }^{5}$ Tables B1 and B2 in Appendix B summarize the Mokken scale analyses of cognitive availability.

${ }^{6} \mathrm{An}$ exploratory factor analysis of the liberal democracy aspirations items also yields a one-factor solution.
} 
Table 2. Polytomous Mokken scale analysis for the calculation of horizontal constraint

\begin{tabular}{llc}
\hline & \multicolumn{2}{c}{ Liberal democracy aspirations } \\
\cline { 2 - 3 } & Mean & Loevinger-H \\
\hline Rule of law & 9.21 & 0.48 \\
Free elections & 8.94 & 0.47 \\
Horizontal accountability & 8.77 & 0.42 \\
Media reliability & 8.73 & 0.5 \\
Vertical accountability & 8.37 & 0.39 \\
Government justification & 8.35 & 0.44 \\
Minorities' rights & 8.3 & 0.41 \\
Parties' freedom & 8.28 & 0.48 \\
Press freedom & 8.23 & 0.45 \\
Differentiated partisan offer & 7.97 & 0.43 \\
Political deliberation & 7.41 & 0.34 \\
Loevinger-H of scalability & & 0.43 \\
\hline
\end{tabular}

Even if it is theoretically informed, this approach to measure horizontal constraint also has a strong inductive component since it is based on the response pattern of all respondents. This is justified by the fact that the hierarchy established by respondents with regards to which are the most and least important principles is coherent with most normative models of democracy (see Hernández, 2016). Principles like the rule of law or free elections are the ones to which respondents attribute a higher importance, and these are, at the same time, the principles that are considered essential in most normative models of democracy. Moreover, there is a very similar hierarchical structuration of democratic aspirations about these liberal democratic principles across the 29 countries included in the sample (see Kriesi et al., 2016). A deductive alternative to measure horizontal constraint that follows a similar logic would be to assess how many times a respondent considers that any liberal principle is more important than the two essential liberal democracy principles (free elections and the rule of law). This follows a logic similar to that of the measure proposed in this section. However, as a difference from the method privileged in this paper, this alternative does not provide a threshold to judge whether the DBS of an individual is horizontally constrained or not, which is relevant to describe the degree of attitudinal constraint of DBS (see below). In any case, Appendix C provides more details about this alternative (deductive) operationalization of horizontal constraint and replicates all the analyses of the correlates of horizontal constraint with this alternative measure. The results obtained with this alternative operationalization lead to similar conclusions.

\section{Vertical constraint}

Different methods have also been proposed to measure vertical constraint. Some have assessed vertical constraint through structural equation models linking superordinate values and issuespecific attitudes (Rohrschneider, 1993; Goren, 2013). Others either relied on the analysis of correlations between superordinate attitudes and issue-specific attitudes or have analyzed the variance explained in issue-specific attitudes by the superordinate attitude (Jennings, 1992; Granberg and Holmberg, 1996). A similar approach is adopted here.

To evaluate the vertical constraint of DBS, the correspondence between individuals' generic preferences to live in a democracy and individuals' specific liberal democratic aspirations is first evaluated by analyzing the correlation between the two. ${ }^{7,8}$ Next, to compute a measure of vertical

\footnotetext{
${ }^{7}$ The generic preference to live in a democracy is measured through a question asking respondents to state 'How important is it for you to live in a country that is governed democratically?'.

${ }^{8}$ To ensure the comparability between the measures of horizontal and vertical constraint the analysis of vertical constraint is also limited to the liberal principles of democracy. The measure of citizens' liberal democratic aspirations is obtained by adding all the principles of the liberal model of democracy included in the Mokken scale of Table 2 and dividing this measure by the number of items (11).
} 
constraint for each respondent, I estimate an ordinary least squares (OLS) model in which liberal democratic aspirations are specified as the dependent variable and the generic preference to live in democracy as the independent variable. In a second step, the absolute value of the residuals of this model is calculated for each respondent. These residuals represent the part of the variation in individuals' democratic aspirations not explained by their generic preference to live in a democracy. The resulting variable is rescaled to range between 0 and 100 and is reversed so that higher values indicate smaller residuals and, therefore, higher vertical constraint.

\section{Model estimation and covariates}

To analyze the individual- and country-level correlates of the articulation of DBS, I estimate random-intercepts linear models with each of the DBS components as the dependent variables. All models include the following individual-level variables: education measured in three categories (primary or less, secondary, university), political interest (measured in four categories ranging from not at all interested in politics to very interested), age, age squared, and gender. At the country level, the historical experience of democracy of a given country is operationalized as the number of years that a country has uninterruptedly been democratic according to Polity IV, with a maximum value of 100 years (the variable included in the models is rescaled to range between 0 and 1). ${ }^{9}$

\section{Results}

\section{The articulation of DBS in Europe}

The first step in the analysis aims to provide a descriptive overview of the articulation of Europeans' DBS. I begin with the analysis of cognitive availability, which is a precondition for the existence of attitudinal constraint. The cognitive availability dimension is rightly skewed with a mean of 95 and a standard deviation of 13 . Hence, cognitive availability is, on average, high. Only $7 \%$ of the sample has a value lower than 80 , which corresponds to having provided a valid answer to 29 of the 36 questions about democratic aspirations and evaluations. In fact, $66 \%$ of the sample has a value of 100 or full cognitive availability. This result indicates that a majority of respondents were able to link each and every principle of democracy to an ideal conceptualization of democracy and to an evaluation of how the same principles are applied in their country.

Table 3 allows us to assess the levels of cognitive availability for each of the principles of democracy. The table reveals that cognitive availability varies widely from one principle to the other. Cognitive availability is higher for basic principles of democracy such as the rule of law or the freedom and fairness of elections. For example, 98\% of citizens are capable of linking these two basic principles to an ideal notion of democracy by stating how important they think these principles are for democracy. This result is quite logical. The fundamental principles of democracy are more frequently discussed in relation to democracy, and therefore, citizens should be more familiar with these principles. There is actually a strong correlation between the average importance attributed to each principle of democracy for an ideal democracy (at the aggregate level) and the levels of cognitive availability for that same principle of democracy in the sample (the correlation between the average importance attributed to a given principle and cognitive availability equals 0.78 for the aspiration items and 0.79 for the evaluation items).$^{10}$ From a normative standpoint, this is a positive result. Most citizens are aware, at least, about the key fundamental elements of democracy. Moreover, Table 1 also reveals that when considering the same principle of

\footnotetext{
${ }^{9}$ The restriction to a maximum of 100 years is justified on theoretical grounds. This variable is included in the models to account for potential institutional learning mechanisms. Therefore, extending it beyond 100 years does not make much sense given the age distribution in the sample.

${ }^{10}$ The average importance is calculated by averaging how important all respondents in the sample consider each principle for an ideal model of democracy.
} 
Table 3. Cognitive availability for particular principles of democracy

\begin{tabular}{lcc}
\hline & \multicolumn{2}{c}{ Cognitive availability } \\
\cline { 2 - 3 } & Aspirations & Evaluations \\
\hline Government responsibility & 91.4 & 86.5 \\
Power sharing & 92.7 & 90.7 \\
Migrants' voting rights & 94.2 & - \\
Horizontal accountability & 95.0 & - \\
Government responsiveness & 95.2 & 92.9 \\
Freedom of expression & 95.4 & 94.7 \\
Differentiated partisan offer & 95.9 & 94.0 \\
Vertical accountability & 96.3 & 93.9 \\
Direct democracy & 96.4 & 94.4 \\
Political deliberation & 96.1 & 94.2 \\
Parties' freedom & 96.5 & 95.5 \\
Minorities' rights & 96.3 & 93.1 \\
Reduction income differences & 97.3 & 96.0 \\
Press freedom & 97.3 & 96.5 \\
Media reliability & 97.7 & 95.8 \\
Government justification & 97.7 & 96.2 \\
Free elections & 97.8 & 96.4 \\
Protection against poverty & 98.2 & 97.7 \\
Rule of law & 98.2 & 95.8 \\
\hline
\end{tabular}

democracy, there is a strong correspondence between cognitive availability for democratic aspirations and evaluations (the correlation between the levels of cognitive availability for aspirations and evaluations for each principle of democracy equals 0.95). If cognitive availability is low for a given democratic principle when it comes to democratic aspirations, cognitive availability is also likely to be low when it comes to democratic evaluations of the same principle of democracy.

Even if the DBS of most citizens is characterized by a wide range of cognitions about democracy, these cognitions might not be coherently structured. To assess this, I first analyze the horizontal constraint of DBS. The horizontal constraint dimension is measured from 0 to 100 , with higher values indicating higher horizontal constraint. The distribution of this variable is also rightly skewed with a mean of 93 and a standard deviation of 10. Although this measure - based on the number of Gutman errors of each individual - is ideal to make comparisons in the levels of horizontal constraint across individuals, it does not directly provide a threshold to characterize whether horizontal constraint is high or low. However, a threshold can be easily established since the number of Gutman errors constitutes the basis for the calculation of $\mathrm{H}$-indexes and therefore, each value in the horizontal constraint dimension can be associated with a specific $\mathrm{H}$-index (Hardouin et al., 2011). A common rule of thumb in Mokken scale analysis is that a set of items has acceptable scalability properties if the H-coefficient of scalability is equal or higher than 0.3 and that a scale is strong if the scalability coefficient is equal or higher than 0.5 . These same thresholds can be used for each individual $\mathrm{H}$-index. In this particular case, the value 91 in the horizontal constraint measure corresponds to an $\mathrm{H}$-index of 0.3 , and the value 93.7 corresponds to an $\mathrm{H}$-index of 0.5. All those respondents with a value equal or higher than 91 can be considered to have a horizontally constrained DBS and those with a value higher than 93.7 can be considered to have a strongly horizontally constrained DBS.

Only $25.5 \%$ of respondents have a value lower than 91 in the horizontal constraint dimension. This implies that a majority of respondents (74.5\%) have a coherent structuration of their democratic aspirations. Even when adopting a more stringent threshold (a value of 93.7 in the horizontal constraint dimension), we find that $65.1 \%$ of respondents have a level of horizontal constraint that surpasses that threshold. Hence, a great proportion of citizens have a DBS with a strong level of horizontal constraint. The direct implication of these findings is that most citizens, no matter how high or low their democratic aspirations are, appear to recognize that there 
are some basic principles of democracy, like free elections, to which they usually attribute a higher or equal importance than to other nonfundamental principles.

The next step in the descriptive analysis consists of examining the extent to which individuals' DBS are vertically constrained. The vertical constraint dimension is also measured from 0 to 100 . This variable has a mean of 89 and a standard deviation of 9 . However, again, while this measure is useful in relative terms (to compare constraint levels between individuals), it does not provide a threshold to judge whether the vertical structuration of DBS is, on average, high or low. A better assessment of Europeans' overall levels of vertical constraint is provided by the correlation between individuals' democratic aspirations and the general importance they attribute to being able to live in a democratic country. This correlation equals 0.44 , and it is statistically significant. Contrasting this level of constraint to comparable studies of PBS, which focus on the correspondence (correlation) between the position of citizens on the left-right dimension and their issue positions on policy issues, the average level of vertical constraint of DBS is similar, or even higher, than the average level of vertical constraint of the PBS analyzed in these early studies (see Granberg and Holmberg, 1996).

The descriptive analysis indicates that Europeans' DBS are broad ranging and coherently structured. However, notwithstanding this high level of DBS articulation, there might still be differences across countries. To provide an integrated comparative outlook of the articulation of DBS across Europe, I examine how countries are grouped together in terms of their citizens' cognitive availability (measured as the proportion of respondents with full cognitive availability), horizontal constraint (measured by the proportion of citizens with a value higher than 91 in the horizontal constraint scale), and vertical constraint (measured by the correlation between individuals' democratic aspirations and the general importance they attribute to being able to live in a democracy in each country). Using these variables, and by means of kmedians cluster analysis, the countries are clustered into three groups. Each group is characterized by a different combination of cognitive availability (CA), horizontal constraint (HC), and vertical constraint (VC).

Figure 1 summarizes the group each country is assigned to, as well as the average levels of each of the three DBS components in each group. The first of these groups (countries colored in light salmon/light grey) is characterized by a high proportion of citizens with full cognitive availability, a high degree of horizontal constraint, and a strong level of vertical constraint. This is what we would consider ideal. However, one must note that this is the group that includes the fewest countries, just 6 . The second group, countries colored in light orange/grey, is also characterized by DBS with a high level of articulation. These 14 countries are characterized by DBS with degrees of horizontal constraint and vertical constraint comparable to those of the first group. However, in these countries, the proportion of citizens with full cognitive availability is substantially lower. The third group of countries, colored in dark orange/black, clearly contrasts with the other two groups since in them DBS are significantly less articulated. A mere half of the population has full cognitive availability, and the levels of vertical constraint are substantially lower than in the other two groups. Moreover, the proportion of citizens with a horizontally constrained DBS is also slightly lower in this third group of countries. The results summarized in Figure 1 indicate that there is variation across Europe in the levels of articulation of DBS. Countries located at the core of Western Europe appear to have the most articulated DBS, followed by other Western and Southern European countries. In contrast, in Eastern Europe, as well as in the Balkans, we find the lowest levels of articulation of DBS. It seems, therefore, that in countries with a shorter democratic tradition the articulation of DBS is lower. ${ }^{11}$

\footnotetext{
${ }^{11}$ As Figure 1 suggests, at the country-level the cognitive availability and attitudinal constraint of DBS are positively related. However, while the correlation between cognitive availability and horizontal constraint is weak $(r=0.23)$, the correlation between cognitive availability and vertical constraint is strong $(r=0.6)$.
} 


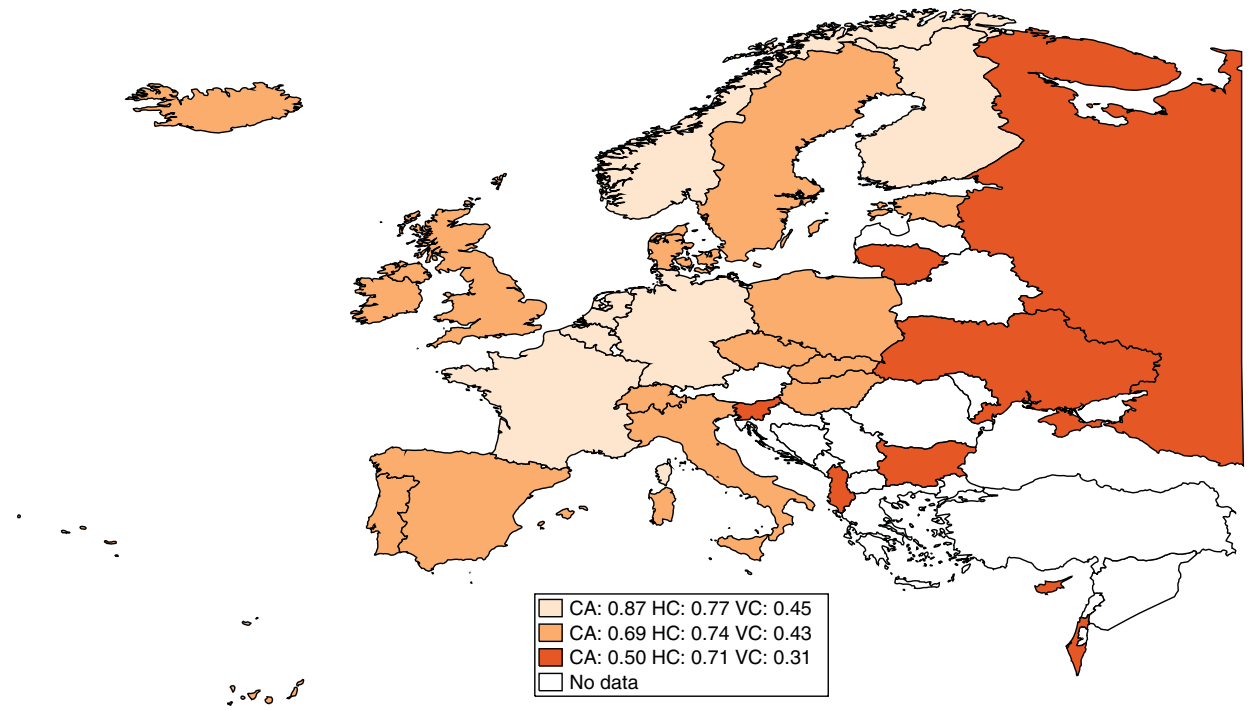

Figure 1. The articulation of democracy belief systems in Europe.

\section{Correlates of the articulation of DBS}

Model 1 in Table 4 summarizes the results of the analysis of the correlates of cognitive availability. The belief systems of those who are more educated are characterized by a wider range of cognitions about democracy. The difference on cognitive availability between those with primary and university education is substantial since it is equivalent to a 0.41 standard deviation change in the cognitive availability index. However, the most relevant individual-level differences in cognitive availability are related to political interest. Moving from being not at all interested in politics to being very interested in politics is related to a positive change of 6.8 units in the cognitive availability index, which is equivalent to an increase of 0.52 standard deviations in this variable. Hence, motivational aspects, captured by political interest, and cognitive abilities, measured by education, are relevant predictors of cognitive availability.

The variable measuring countries' historical experience of democracy accounts for potential institutional learning mechanisms. This variable ranges from 0 to 1 , with higher values indicating a more prolonged experience of democracy. The results indicate that in countries with a longer tradition of democracy individuals have a broader range of cognitions about democracy. Moving from the country with the shortest experience of democracy to the one with the longest is related to an increase of 2.6 units in the cognitive availability dimension. Although of moderate magnitude, this effect contrasts with the findings of Dalton et al. (2008), who argued that democratic experience had no impact on citizens' awareness about democracy.

The increasing opportunities to learn about democracy in countries with a longer democratic tradition are expected to reduce the inequalities in cognitive availability related to education. To test this, I fit a cross-level interaction between individuals' level of education and countries' historical experience of democracy through a random intercepts and random slopes multilevel model (see Table $\mathrm{C} 1$ in the Appendix). Figure 2 summarizes how the gap in cognitive availability between those with different levels of education changes as a function of countries' historical experience of democracy. The first panel of Figure 2 summarizes the differences in cognitive availability between those with university and primary education. As expected, these differences are high in those countries with a short experience of democracy, and they become substantially smaller as the number of years that a country has been a democracy increases. A similar result is obtained when 
Table 4. The correlates of cognitive availability and attitudinal constraint in democracy belief systems

\begin{tabular}{|c|c|c|c|c|}
\hline & $\begin{array}{l}\text { (1) Cognitive } \\
\text { availability }\end{array}$ & $\begin{array}{l}\text { (2) Horizontal } \\
\text { constraint }\end{array}$ & $\begin{array}{l}\text { (3) Vertical } \\
\text { constraint }\end{array}$ & $\begin{array}{l}\text { (4) Vertical } \\
\text { constraint }\end{array}$ \\
\hline \multicolumn{5}{|l|}{ Individual-level variables } \\
\hline \multicolumn{5}{|c|}{ Education (reference: primary) } \\
\hline Secondary & $\begin{array}{l}4.12^{\star \star} \\
(0.19)\end{array}$ & $\begin{array}{l}0.77^{\star \star} \\
(0.17)\end{array}$ & $\begin{array}{l}1.19^{\star \star} \\
(0.16)\end{array}$ & $\begin{array}{l}1.12^{\star \star} \\
(0.16)\end{array}$ \\
\hline University & $\begin{array}{l}5.14^{\star *} \\
(0.21)\end{array}$ & $\begin{array}{l}1.37^{\star \star} \\
(0.19)\end{array}$ & $\begin{array}{l}2.40^{\star \star} \\
(0.17)\end{array}$ & $\begin{array}{l}2.27^{\star *} \\
(0.17)\end{array}$ \\
\hline \multicolumn{5}{|c|}{ Political interest (reference: not interested) } \\
\hline Hardly interested & $\begin{array}{l}5.29^{\star \star} \\
(0.15)\end{array}$ & $\begin{array}{l}0.83^{\star \star} \\
(0.13)\end{array}$ & $\begin{array}{l}1.32^{\star \star} \\
(0.12)\end{array}$ & $\begin{array}{l}1.24^{\star \star} \\
(0.12)\end{array}$ \\
\hline Quite interested & $\begin{array}{l}6.65^{\star \star} \\
(0.15)\end{array}$ & $\begin{array}{l}1.30^{\star \star} \\
(0.14)\end{array}$ & $\begin{array}{l}2.15^{\star \star} \\
(0.12)\end{array}$ & $\begin{array}{l}2.03^{\star \star} \\
(0.12)\end{array}$ \\
\hline Very interested & $\begin{array}{l}6.82^{\star \star} \\
(0.21)\end{array}$ & $\begin{array}{l}0.79^{\star \star} \\
(0.18)\end{array}$ & $\begin{array}{l}2.10^{\star \star} \\
(0.16)\end{array}$ & $\begin{array}{l}2.02^{\star \star} \\
(0.16)\end{array}$ \\
\hline Age & $\begin{array}{l}0.31^{\star \star} \\
(0.01)\end{array}$ & $\begin{array}{l}0.05^{\star \star} \\
(0.01)\end{array}$ & $\begin{array}{l}0.05^{\star \star} \\
(0.01)\end{array}$ & $\begin{array}{l}0.05^{\star \star} \\
(0.01)\end{array}$ \\
\hline $\mathrm{Age}^{2}$ & $\begin{array}{c}-0.00^{* *} \\
(0.00)\end{array}$ & $\begin{array}{c}-0.00^{* *} \\
(0.00)\end{array}$ & $\begin{array}{c}-0.00^{\star *} \\
(0.00)\end{array}$ & $\begin{array}{c}-0.00^{* *} \\
(0.00)\end{array}$ \\
\hline Female & $\begin{array}{c}-1.76^{\star *} \\
(0.10)\end{array}$ & $\begin{array}{l}0.56^{\star \star} \\
(0.09)\end{array}$ & $\begin{array}{c}0.03 \\
(0.08)\end{array}$ & $\begin{array}{l}-0.03 \\
(0.08)\end{array}$ \\
\hline Horizontal constraint & & & & $\begin{array}{l}0.10^{\star \star} \\
(0.00)\end{array}$ \\
\hline \multicolumn{5}{|l|}{ Country-level variables } \\
\hline $\begin{array}{l}\text { Historical experience } \\
\text { democracy }\end{array}$ & $\begin{array}{l}2.56^{\star} \\
(1.27)\end{array}$ & $\begin{array}{c}0.29 \\
(0.70)\end{array}$ & $\begin{array}{l}3.55^{\star \star} \\
(0.87)\end{array}$ & $\begin{array}{l}3.52^{\star *} \\
(0.85)\end{array}$ \\
\hline Constant & $\begin{array}{c}82.30^{\star *} \\
(0.80)\end{array}$ & $\begin{array}{c}88.64^{\star \star} \\
(0.52)\end{array}$ & $\begin{array}{c}84.01^{\star \star} \\
(0.57)\end{array}$ & $\begin{array}{c}75.43^{\star \star} \\
(0.67)\end{array}$ \\
\hline \multicolumn{5}{|l|}{ Random-effects parameters } \\
\hline $\begin{array}{l}\text { SD constant (random } \\
\text { intercept) }\end{array}$ & $\begin{array}{l}2.05^{\star \star} \\
(0.27)\end{array}$ & $\begin{array}{l}1.12^{\star \star} \\
(0.15)\end{array}$ & $\begin{array}{l}1.41^{\star \star} \\
(0.19)\end{array}$ & $\begin{array}{l}1.37^{\star \star} \\
(0.18)\end{array}$ \\
\hline Observations & 52,379 & 47,293 & 46,810 & 46,810 \\
\hline Number of groups & 29 & 29 & 29 & 29 \\
\hline
\end{tabular}

Standard errors in parentheses ** $\mathrm{p}<0.01,{ }^{*} \mathrm{p}<0.05$.

assessing the change in the differences in cognitive availability between those with secondary and primary education. In fact, in the contexts with the longest historical experience of democracy (countries that have been uninterruptedly democratic for 80 years or longer), the differences in cognitive availability between those with primary education and those with secondary or university education are not statistically significant. Overall, these results support the idea that in contexts in which information about democracy is more readily available, inequalities in cognitive availability become smaller. However, this is only the case when comparing those with primary education to those with university or secondary education. As reflected in the third panel of Figure 2, the differences in cognitive availability between those with secondary and university education are not moderated by democratic experience. This is probably because the differences in cognitive availability between these two groups are of reduced magnitude (around one point, on average). Therefore, inequalities in cognitive availability related to education only seem to be apparent with respect to those who are least educated and in contexts of limited democratic experience. As a consequence, these inequalities should diminish over time, as countries' democratic experience increases and as people become more educated.

Model 2 in Table 4 summarizes the correlates of horizontal constraint. This model reveals that even if education and political interest are positively related to the horizontal constraint of DBS, the effect of these variables is negligible. Even though the coefficients of these variables are statistically significant, their substantive impact on horizontal constraint is very limited. For example, 


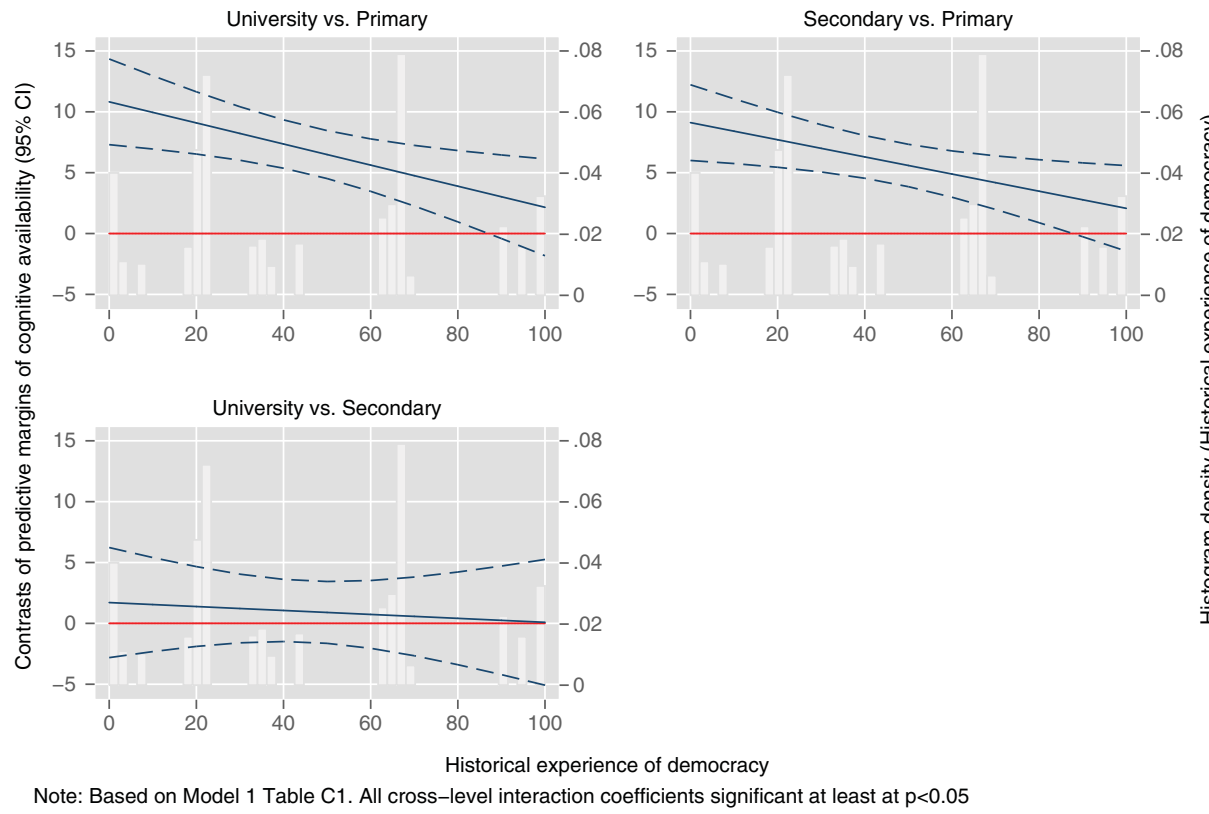

Figure 2. Contrasts of predictive margins of cognitive availability between different levels of education as a function of countries' historical experience of democracy.

moving from primary to university education is just associated with a 0.14 standard deviation change in horizontal constraint. At the country level, there are no significant differences in the extent to which DBS are horizontally constrained as a function of countries' historical experience of democracy. Hence, there is no substantial variation in levels of horizontal constraint across population subgroups. ${ }^{12}$ Moreover, in this case, the historical experience of democracy does not moderate the educational differences in levels of horizontal constraint (see Model 2 in Table $\mathrm{C} 1$ in the Appendix). This is not surprising, since, to start with, the differences between those with the lowest and the highest levels of education are of reduced magnitude when it comes to horizontal constraint.

Turning now to the analysis of the correlates of vertical constraint, Model 3 in Table 4 indicates that, in this case, education appears to have a slightly more relevant impact. Moving from primary to university education is related to an increase of 2.4 units in the measure of vertical constraint, which is equivalent to an increase of 0.27 standard deviations in this variable. The same occurs in the case of political interest, since the DBS of those who are more interested in politics are more vertically constrained. However, the most relevant difference between the horizontal constraint and vertical constraint models relates to the impact of countries' democratic trajectory. In countries with a prolonged experience of democracy, the vertical constraint of DBS is substantially higher. Moving from the country with the shortest historical experience of democracy to the one with the longest implies an increase in the level of vertical constraint of 3.5 units (equivalent to a 0.40 standard deviation change in the vertical constraint variable). However, in this case, the historical experience of democracy does not moderate the educational differences in vertical constraint (see Model 3 in Table $\mathrm{C} 1$ in the Appendix).

\footnotetext{
${ }^{12}$ Similar conclusions are reached if instead of a continuous measure of horizontal constraint the variable is dichotomized so that it takes the value 1 for those with a horizontal constraint value higher or equal than 91 or 93.7 (equivalent to a 0.3 and 0.5 Loevinger H-coefficient, respectively) and the value 0 otherwise (see Figure D2 in Appendix D).
} 
The results for vertical constraint indicate that in countries with a longer democratic trajectory, citizens have a stronger correspondence between their specific democratic aspirations and their generic preference to live in a democracy. However, these results might be driven by the fact that these democratic aspirations exclusively refer to the liberal model of democracy. The meaning citizens attribute to democracy might be contextually contingent. Citizens living in countries with a shorter democratic trajectory could have a different conception of democracy, which might not be liberal. If that was the case, their DBS might still have a high level of vertical constraint, but that would not be reflected in the measure implemented in this paper. With the ESS data, it is not possible to fully rule out this alternative explanation, since this dataset only includes a limited number of indicators for alternative models of democracy. However, I asses the plausibility of this rival explanation by analyzing the correlates of vertical constraint through an alternative operationalization. This measure of vertical constraint is estimated as the original one, but besides the eleven items measuring aspirations related to the liberal model of democracy it also includes two items related to aspirations about the social-justice model of democracy (reduction of income differences and protection against poverty) and one item related to aspirations about the direct-democratic model of democracy. The results obtained with this alternative operationalization lead to the same conclusions about the effects of countries' historical experience of democracy, as well as about the other correlates of vertical constraint (see Appendix E). Therefore, it seems that the DBS of those living in countries with a longer experience of democracy are more vertically constrained, even when accounting for models of democracy beyond the liberal one.

I specify a final model (Model 4) to analyze the relationship between horizontal constraint and vertical constraint. These two elements should be positively related, since both capture the coherent structuration of DBS. Model 4 reveals that this is the case. Those citizens who have a more coherent structuration of their democratic aspirations (horizontal constraint) are also more likely to have a greater correspondence between these aspirations and their more abstract values about democracy (vertical constraint). This is hardly surprising since a noncoherent structuration of specific democratic aspirations should prevent a strong correspondence with any other more general attitude.

\section{Conclusion}

In a context of declining support for democratic values, increasing democratic discontent, and increasing support for populist forces, there is a growing interest in assessing what citizens think about democracy (Foa and Mounk, 2017). However, gauging citizens' opinions about a complex concept such as democracy might be hindered by the apparent low levels of political sophistication of mass publics and the lack of structure of their belief systems (Klingemann, 1979; Delli Carpini and Keeter, 1996). This paper contributes to this debate by analyzing the extent to which mass publics are capable of developing structured attitudes about an abstract political domain such as democracy.

For this purpose, the paper adapts Converse's PBS analytical framework to conceptualize belief systems about democracy. Drawing on the concept of PBS, I argue that DBS are formed by two main components: the number of cognitions or attitudes about democracy available in individuals' belief systems and the constraint of these attitudes. The latter component is divided into two subcomponents: horizontal constraint and vertical constraint.

The main conclusion is that, when considering its three components, the DBS of most Europeans appear to be broad ranging and coherently organized. Specifically, the empirical analyses of this paper reveal, first, that most individuals have a broad number of cognitions about democracy available in their belief systems. However, limiting the analysis of DBS to cognitive availability would be inadequate, since individuals' cognitions or attitudes may not be coherently structured. The analysis of the constraint of DBS reveals that this is not generally the case. Individuals' democratic aspirations are both horizontally and vertically constrained. For a 
majority of individuals, specific democratic aspirations are coherently structured, and these specific aspirations are also related, in a predictable way, to generic attitudes toward democracy. These findings defy the pessimistic views about the reduced political sophistication and lack of structure of belief systems of mass publics and indicate that, in line with the most recent evidence based on other policy domains, the belief systems of individuals are much more structured than it was previously assumed (see, e.g., van Elsas, 2015; Freeze and Montgomery, 2016).

It is important to note, though, a limitation of these measures that could lead to an overestimation of attitudinal constraint. Since full cognitive availability is a prerequisite for the measurement of attitudinal constraint, these results are restricted to the subsample of respondents who did not provide any don't know answer for any of the liberal democratic aspirations items used to operationalize vertical constraint and horizontal constraint. ${ }^{13}$ Since cognitive availability is positively related to factors like education, the estimated levels of constraint might be overestimated. In any case, this paper has gone beyond most previous analyses of PBS by first analyzing cognitive availability and showing that, in the case of DBS, cognitive availability is significantly related to factors such as education or political interest.

Notwithstanding the high levels of articulation of DBS, there are also some differences in the articulation of DBS across countries and individuals. Those who are more educated, more politically interested, or live in countries where opportunities to be exposed to information about democracy are greater have higher levels of cognitive availability and vertical constraint. However, the strength of these relationships is modest. Moreover, in the case of horizontal constraint, the effects of education or political interest are also in the expected direction, but these effects do not appear to be substantively relevant. The reduced impact of these variables is in line with recent studies of PBS in other domains, which conclude that the constraint and structuration of political attitudes is not closely related to factors like education or political awareness (Goren, 2013; van Elsas, 2015).

These findings have relevant implications for future analyses of Europeans' views of democracy. First, the fact that most of those who provide an answer to questions about their democratic aspirations appear to do so in a coherent way should allow researchers to meaningfully analyze these attitudes as well as their consequences. Second, since horizontal constraint is only modestly related to attributes such as political interest or education, studies analyzing the impact of these factors on democratic aspirations (e.g., Ceka and Magalhães, 2016) should capture meaningful relations that are not generated by the more coherent structuration of these attitudes among the highly educated and interested. However, a third finding of this paper is that even if cognitive availability is on average high, those who are more educated and interested in politics tend to have significantly higher levels of cognitive availability. This implies that researchers relying on these survey items will underrepresent certain sociodemographic groups, especially in countries located in Eastern Europe and the Balkans.

Different avenues for further research can be suggested as a result of the limitations of this paper. First, this paper focuses on European countries, which may be a propitious region to find highly articulated DBS, due to the prolonged democratic trajectory of most countries. Further analyses could extend the geographical scope relying on sources like the World Values Survey. Second, due to data restrictions, and with the exception of the cognitive availability dimension, most of the analyses are limited to the liberal dimension of democracy. Further research should consider alternative models of democracy.

Notwithstanding these limitations, the findings of this paper have relevant implications that go beyond the study of individuals' attitudes toward democracy. Knowing that citizens have a

\footnotetext{
${ }^{13}$ This implies that approximately $12 \%$ of the original sample is not included in the analyses of horizontal and vertical constraint. To provide a more detailed analysis of Europeans' DBS, in Appendix F I conduct a separate analysis of the correlates of vertical and horizontal constraint at different levels of cognitive availability. These results do not alter the conclusions about the correlates of vertical and horizontal constraint.
} 
coherent structuration of their beliefs about democracy is important to attempt to explain phenomena such as the increasing support for illiberal movements and parties, and the corresponding threat of democratic backsliding. For example, the resistance to democratic backsliding in different countries might depend on the way in which citizens think about democracy in each country. Moreover, if citizens have structured preferences about democracy, they can be effectively included in the debate about how liberal democracies can be reformed in order to confront these threats.

Acknowledgements. This research has received financial support from the Spanish Ministry of Science, Innovation, and Universities through research grant CSO2017-83086-R. I am grateful to Macarena Ares, Hanspeter Kriesi, Pedro Magalhães, Mariano Torcal, the editors and four anonymous reviewers of the European Political Science Review, and participants at the 2018 European Consortium for Political Research General Conference and the 2018 ESS Spanish Congress for helpful comments and suggestions.

Supplementary material. To view supplementary material for this article, please visit https://oi.org/10.1017/ S1755773919000286

\section{References}

Berinsky, A.J. (2005), Silent Voices: public Opinion and Political Participation in America, Princeton, NJ: Princeton University Press.

Bizer, G.Y., P.S. Visser, M.K. Berent and J.A. Krosnick (2004), Importance, knowledge, and accessibility: exploring the dimensionality of strength-related attitude properties, in Saris, W.E. and P.M. Sniderman (eds), Studies in Public Opinion: attitudes, Nonattitudes, Measurement Error, and Change, Princeton, NJ: Princeton University Press, pp. 215-242.

Bratton, M., R.B. Mattes and E. Gyimah-Boadi (2005), Public Opinion, Democracy, and Market Reform in Africa, Cambridge Studies in Comparative Politics, Cambridge: Cambridge University Press.

Ceka, B. and P. Magalhães (2016), How people understand democracy: a social dominance approach, in Ferrín, M. and H. Kriesi (eds), How Europeans View and Evaluate Democracy, Oxford: Oxford University Press, pp. 90-111.

Converse, P.E. (1964), The nature of belief systems in Mass publics, in D.E. Apter (ed.), Ideology and Discontent, New York, NY: Free Press, pp. 206-261.

Converse, P.E. (1970), Attitudes and non-attitudes: continuation of a dialogue, in E.R. Tufte (ed.), The Quantitative Analysis of Social Problems, Addison-Wesley Series in Behavioural Science, Quantitative methods, Reading, MA; London: AddisonWesley, pp. 168-189.

Dalton, R.J. and D.C. Shin (2014), Reassessing the civic culture model, in Dalton, R.J. and C. Welzel (eds), The Civic Culture Revisited: from Allegiant to Assertive Citizens, Cambridge: Cambridge University Press, pp. 91-116.

Dalton, R.J., D.C. Shin and W. Jou (2008), How people understand democracy, in Diamond, L. and M.F. Plattner (eds), How People View Democracy, Baltimore: John Hopkins University Press, pp. 1-16.

Delli Carpini, M.X. and S. Keeter (1996), What Americans know about politics and why it matters, New Haven: Yale University Press.

Eagly, A.H. and S. Chaiken (1993), The Psychology of Attitudes, Fort Worth, TX: Harcourt Brace Jovanovich College Publishers.

Ferrín, M. (2012), What is Democracy to Citizens?: understanding Perceptions and Evaluations of Democratic Systems in Contemporary Europe, Florence: European University Institute.

Ferrín, M. and H. Kriesi (2016), How Europeans View and Evaluate Democracy, Oxford: Oxford University Press.

Foa, R.S. and Y. Mounk (2017), 'The signs of deconsolidation', Journal of Democracy 28, 5-15.

Fraile, M. (2013), 'Do information-rich contexts reduce knowledge inequalities? The contextual determinants of political knowledge in Europe', Acta Politica 48, 119-143.

Freeze, M. and J.M. Montgomery (2016), 'Static stability and evolving constraint preference stability and ideological structure in the Mass public', American Politics Research 44, 415-447.

Fuchs, D. (1999), The democratic culture of unified Germany, in P. Norris(ed.), Critical Citizens: Global Support for Democratic Government, Oxford; New York: Oxford University Press, pp. 123-146.

Gómez, B. and I. Palacios (2016), Citizens' evaluations of democracy. A microscope with quality seal, in Ferrín, M. and H. Kriesi (eds), How Europeans View and Evaluate Democracy, Oxford: Oxford University Press, pp. 155-178.

Goren, P. (2013), On Voter Competence, Oxford: Oxford University Press.

Granberg, D. and S. Holmberg (1996), 'Attitude constraint and stability among elite and mass in Sweden', European Journal of Political Research 29, 59-72.

Hardouin, J.-B., A. Bonnaud-Antignac and V. Sébile (2011), 'Nonparametric item response theory using Stata'. The Stata Journal 11, 30-51. 
Hernández, E. (2016), Europeans' views of democracy: the core elements of democracy, in Ferrín, M. and H. Kriesi (eds), How Europeans View and Evaluate Democracy, Oxford: Oxford University Press, pp. 43-64.

Hernández, E. (2018), 'Democratic discontent and support for mainstream and challenger parties: democratic protest voting', European Union Politics 19, 458-480.

Hurwitz, J. and M. Peffley (1987), 'How are foreign policy attitudes structured? A hierarchical model', The American Political Science Review 81, 1099-1120.

Jennings, M.K. (1992), 'Ideological thinking among Mass publics and political elites', Public Opinion Quarterly 56, 419-441.

Klingemann, H.-D. (1979), Measuring ideological conceptualization, in Barnes, S.H., M. Kaase and K.R. Allerbeck (eds), Political Action: Mass Participation in Five Western Democracies. Beverly Hills, CA: Sage Publications, pp. 215-255.

Kriesi, H., W. Saris and P. Moncagatta (2016), The strucuture of Eruropeans' views of democracy: citizens' models of democracy, in Ferrín, M. and H. Kriesi (eds), How Europeans View and Evaluate Democracy?, Oxford: Oxford University Press, pp. 64-90.

Luskin, R.C. (1987), 'Measuring political sophistication', American Journal of Political Science, 31 (4), 856-899.

Mokken, R.J. (1971), A Theory and Procedure of Scale Analysis: with Applications in Political Research, Methods and Models in the Social Sciences, Mouton: The Hague.

Nie, N.H., J. Junn and K. Stehlik-Barry (1996), Education and Democratic Citizenship in America, Chicago; London: University of Chicago Press.

Oser, J. and M. Hooghe (2018), 'Democratic ideals and levels of political participation: the role of political and social conceptualisations of democracy', The British Journal of Politics and International Relations 20, 711-730.

Quaranta, M. (2018), 'How citizens evaluate democracy: an assessment using the European Social Survey', European Political Science Review 10, 191-217.

Rohrschneider, R. (1993), 'Environmental belief systems in Western Europe a hierarchical model of constraint', Comparative Political Studies 26, 3-29.

Rohrschneider, R. (1999), Learning Democracy: democracy and Economic Values in Unified Germany, Comparative European Politics, New York, NY: Oxford University Press.

Torcal, M. (2006), Political disaffection and democratization history in new democracies, in Torcal, M. and J.R. Montero (eds), Political Disaffection in Contemporary Democracies: Social Capital, Institutions, and Politics, Routledge Research in Comparative Politics, London; New York, NY: Routledge, pp. 157-190.

van Elsas, E. (2015), 'Political trust as a rational attitude: a comparison of the nature of political trust across different levels of education', Political Studies 63, 1158-1178.

Cite this article: Hernández E (2019). Democracy belief systems in Europe: cognitive availability and attitudinal constraint. European Political Science Review 11, 485-502. https://doi.org/10.1017/S1755773919000286 